\title{
EDUCATION AND TRAINING Training educational supervisors to support physician trainees returning to practice
}

\author{
Authors: Rosalyn Hallewell, ${ }^{\mathrm{A}}$ Catherine Bryant, ${ }^{\mathrm{B}}$ Andrew Deaner, ${ }^{\mathrm{C}}$ Ruth Ruggles ${ }^{\mathrm{D}}$ and Jonathan Birns ${ }^{\mathrm{E}}$
}

Physicians take time out of training for a variety of reasons and, on their return, they often lack confidence and feel 'out of touch'. These trainees require enhanced support and concerns have been raised about trainers' lack of skills and knowledge in this area. A standardised workshop was developed and delivered to address this with a mixed-methods evaluation approach used to analyse data from participants before and after training. Quantitative analysis showed significant pre- to post-course improvements in trainers' ability to understand, explain and manage issues pertaining to trainees taking time out of training. Qualitative analysis yielded three 'learning' themes surrounding knowledge, understanding and awareness of support needed for returning trainees and three 'action' themes surrounding disseminating information, providing resources and actively supporting returning trainees. Framework analysis of follow-up interviews demonstrated not only retention of topics learned but also positive changes in behaviour.

KEYWORDS: Returning to practice, trainees, training, out of programme, OOP

DOI: 10.7861/fhj.2019-0043

\section{Introduction}

Physicians take time out of training for a number of reasons including parental leave, health-related absence and approved learning opportunities in research, education, leadership or other disciplines that nurture personal development. ${ }^{1}$ Approximately $10 \%$ of postgraduate doctors in training are currently on approved out-of-programme time in research (OOPR), clinical experience (OOPE), clinical training (OOPT) or career break (OOPC). ${ }^{2}$ This

Authors: ${ }^{A}$ supported return to training fellow, Health Education England, London, UK; ${ }^{\mathrm{B}}$ deputy head of School of Medicine, Health

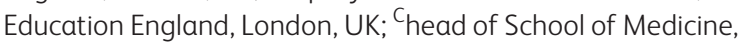
Health Education England, London, UK; 'Dassociate dean, Health Education England, London, UK; ${ }^{E}$ deputy head of School of Medicine, Health Education England, London, UK and consultant in stroke medicine, geriatrics and general medicine, St Thomas' Hospital, London, UK proportion, however, has significant geographic variation, with a greater number of OOPR trainees in London training schemes compared with other regions, for example. Furthermore, national data have shown the medical specialties of infectious diseases, cardiology and medical oncology to have the highest percentage of trainees completing clinical or academic research. ${ }^{3}$

Times of transition in clinical training have been demonstrated to be stressful and associated with increased rates of psychiatric morbidity. ${ }^{4,5}$ While out of programme, trainees may feel a loss of momentum with regard to career progression and/or a sense of professional isolation. On returning to practice, trainees may feel 'out of touch' with advances in practice and clinical developments which may, in turn, lead to a perceived lack of competence in what may be 'dormant' generic and specialty knowledge and skills. In comparison with activities when out of programme, the 'cut and thrust' of hospital medicine offers a contrasting work pattern, change of pace, new unpredictability and lack of personal autonomy which may require some readjustment and reflection. Trainees returning from OOPC or OOPR may also experience additional time demands, such as new or existing childcare responsibilities or the need to write up clinical or academic research. ${ }^{6}$ The longer a doctor is out of programme, the more likely they are to have poor performance ratings on their return with $67 \%$ being found to have educational needs requiring moderate to considerable re-education or training. ${ }^{1,6,7}$ Such challenges have led to the development of programmes to support doctors in training taking career breaks to optimise management of their absence and subsequent return to practice. ${ }^{2,7-9}$ To date, there has been an emphasis on educational events, production of 'return to practice' guidebooks and creation of peer-support networks for trainees., ${ }^{3,8,9}$ While these resources have been well received, there has been a lack of infrastructure to educate and support supervisors of doctors taking time out of training. ${ }^{2}$ Concerns have been raised about how a lack of knowledge and understanding among trainers may have a negative impact upon trainees' experience of returning to training and it has been recommended that training supervisors could improve trainee outcomes in terms of confidence and meeting training needs. ${ }^{10,11}$ This article describes the feasibility and benefits of the development of a learning programme for consultant physicians supervising trainees returning to practice.

\section{Methods}

A standardised half-day workshop was developed by an interdisciplinary working group of educationalists and physicians 


\section{Box 1. Learning outcomes of the workshop}

To improve trainer awareness of the reasons and rules for physicians taking time out of training.

To provide tools and resources to support educational supervisors of returning trainees.

To improve the confidence and competence of physician trainers supervising trainees returning to practice.

from various specialties. The learning outcomes for the workshop were identified (Box 1) and the working group met to formulate its structure (Box 2). Standardised case studies were generated by the working group to reflect the major needs of trainees returning to practice after research, parental leave and sickness, respectively (supplementary material S1). These were 'worked though' in small groups after which course attendees were prompted to identify common themes and areas of difference in their groups and feed back about what they learned about their roles. Trained facilitators led a discussion around these issues and the implications of time out of training on trainees' skills and abilities as well as training programmes (Box 2). The workshop was delivered on three separate occasions over a 1-month period in a standardised fashion by faculty from Health Education England's (HEE's) School of Medicine and Supported Return to Training (SuppoRTT) team in London.

Course attendees were asked to complete validated pre- and post-course questionnaires (supplementary material S2) to:

$>$ rate their confidence (on a scale from 0-100) in five areas related to managing trainees returning to practice and taking a leadership role in supporting returning trainees

$>$ evaluate the course's educational value (in terms of relevance, interest and ability to meet learning outcomes; rated on a scale from 0-100)

> provide 'free-text' feedback regarding what they hoped to achieve, what they learned from the course and ideas for improvement.

Course attendees were then contacted for a follow-up interview 3 months later, primarily to assess for retention of the topics from the training day and changes in behaviour. ${ }^{12}$ Semi-structured telephone interviews were completed using progressive cues

\section{Box 2. Workshop structure}

Welcome, introduction and outline.

Plenary session about Health Education England's SuppoRTT programme, incorporating its rationale and infrastructure.

Plenary session about the resources available to trainers supervising trainees returning to practice and how to access them.

Small group case-based work focusing on the needs of trainees and trainers, using standardised cases.

Group discussion of the implications of time out of training on trainees' clinical and non-clinical skills and on local and regional training programmes.

Plenary session on future action planning for trainers supervising trainees returning to practice. to move from general ideas on the course to specific feedback on learning, including reflections on whether and how learning outcomes had been met; what information had been retained; changes in behaviour; personal development and motivation; and action plans. A standardised template was used to record the course participants' responses (supplementary material S3).

Quantitative data were tested for normality using the Kolmogorov-Smirnov test, subsequent to which continuous parametric data were compared using Student's t-test. Openended responses from pre- and post-course questionnaires and from follow-up interviews were transcribed into a spreadsheet with each response kept as separate datum point. Semi-structured interviews were analysed using a framework analysis method, which involved familiarisation with the data; inductive and deductive coding; development of a framework; application of the framework; data charting; and interpretation of the data. ${ }^{13}$ This provided a means of exploring the experiences of individual interviewees and comparing similarities and differences in perspectives. Initial coding and framework development were completed by one author with themes, codes and framework then being discussed and checked by a different author and, if necessary, recoded as appropriate. Thematic analysis was employed as a primary evaluation of data collection in view of the opportunity to "generate interesting findings beyond the specific research questions for which the study was designed'. ${ }^{14}$ All candidates gave written informed consent to be contacted for follow-up interview and for feedback data to be aggregated for research purposes in accordance with the terms of the Data Protection Act 1998.

\section{Results}

Thirty-seven consultant educational supervisors attended three courses and thematic analysis of their pre-course 'hopes' demonstrated a desire to gain knowledge of the processes and resources available, understand the issues faced by trainees and trainers, and be able to manage a returning trainee. Free text responses to written post-course feedback yielded 114 separate responses which were coded into 261 initial codes within 15 groups that were then separated into three major 'learning' themes of 'knowledge of what's available to support returning trainees'; 'understanding how best to support trainees personally'; and 'how to change culture and improve awareness' and three major themes regarding 'actions to take forward' of 'disseminating information directly'; 'supporting trainees through meetings'; and 'provision of resources for trainees and trainers' (Table 1).

Quantitative analysis showed a significant pre- to post-course improvement in attendees' level of understanding of the SuppoRTT process as well as their confidence to explain the reasons why trainees might take time out of training and the importance of supporting returning trainees, managing trainees returning to practice, signposting trainees and colleagues to appropriate resources, taking a leadership role in supporting returning trainees and developing 'return to training' resources (Table 2). The greatest change was in attendees' level of understanding of the SuppoRTT process. Post-course analysis also showed delegates to be satisfied with the course in terms of its relevance, interest and ability to meet the perceived learning outcomes (mean (standard deviation (SD)); satisfaction score $86 \%$ (13.8)). Framework analysis of semi-structured follow-up interviews 
Table 1. Examples of learning and action themes from post-course questionnaires

\section{'Learning' themes}

Knowledge of what's available to support returning trainees: Better knowledge of infrastructure available for trainees.

Better understanding of the best practice in this area and resources available.

Understanding formalised system of support/pathways for returning trainees.

Understanding how best to support trainees personally: Better understanding of SuppoRTT and to be able to advise my trainees appropriately.

Signposting to relevant resources.

Better understanding of questions and considerations of preabsence and pre-return meetings with trainees.

How to change culture and improve awareness:

How to support work environment ... and work atmosphere.

Engaging trusts to support trainees returning to practice.

\section{'Action' themes}

Disseminating information:

I will ensure that my trainees and colleagues are aware of the SuppoRTT programme.

I will present the learning from today at our next faculty meeting.

Importance of supervisors in disseminating this info.

Directly supporting trainees through meetings:

Interviews with trainees pre- and post-OOP.

Greater awareness of how to do pre- and post-return to practice meetings.

Meetings and checklists aid in planning pre- and post-return to practice meetings.

Provision of resources for trainees and trainers:

Able to provide more focused advice in relation to specific sources of funding available to support trainees returning to practice.

Make sure every trainee has a tailored programme.

Create educational supervisor development.

$\mathrm{OOP}=$ out of programme; SuppoRTT = Supported Return to Training.

revealed 103 initial codes within eight groups that were then separated into five themes (Box 3).

\section{Discussion}

This study demonstrated the feasibility of an educational initiative to improve consultant trainers' understanding of the issues faced by physician trainees returning to practice and increase their confidence in managing these trainees. Significant improvements were demonstrated in many areas of responsibility of the consultants supervising trainees returning to practice; this being suggested to have a positive potential impact on trainees' confidence at a vulnerable time when they have increased expectations of clinical responsibility. ${ }^{4,5,11}$ Optimising a supportive and nurturing environment for such trainees is crucial to ensuring their welfare.

Course participants appreciated the practical approach employed and the potential to share ideas with their peers in addition to the opportunity to offer suggestions for further development of SuppoRTT strategies in the future, including information sharing, use of e-portfolios and inclusion of time out of training in annual review of competence progression discussions. Considering the General Medical Council and HEE's move towards more flexibility in training and the higher numbers of women in medicine, increasing numbers of trainees are likely to take breaks and therefore improving the infrastructure around this would be a sensible move, making things easier for both trainees and trainers. ${ }^{15-17}$

\section{Table 2. Pre- and post-course confidence ratings}

\begin{tabular}{|c|c|c|c|}
\hline & $\begin{array}{l}\text { Pre-course score, \%, } \\
\text { mean (SD) }\end{array}$ & $\begin{array}{l}\text { Post-course score, } \% \text {, } \\
\text { mean (SD) }\end{array}$ & $\mathrm{p}$ value \\
\hline Level of understanding of the SuppoRTT programme & $31.8(24.6)$ & $80.8(11.9)$ & $<0.001$ \\
\hline $\begin{array}{l}\text { Confidence to explain the reasons why trainees might take time out } \\
\text { of training }\end{array}$ & $74.7(14.3)$ & $90.6(7.2)$ & $<0.001$ \\
\hline $\begin{array}{l}\text { Confidence to manage a trainee returning to practice after time out } \\
\text { of training }\end{array}$ & $53.1(21.5)$ & $83.4(11.1)$ & $<0.001$ \\
\hline $\begin{array}{l}\text { Confidence to signpost trainees and colleagues to appropriate } \\
\text { resources to help with return to training }\end{array}$ & $43.9(20.0)$ & $86(12.2)$ & $<0.001$ \\
\hline $\begin{array}{l}\text { Confidence to explain the importance of supporting returning } \\
\text { trainees to patient safety and staff wellbeing/retention }\end{array}$ & $62(20.4)$ & $89.1(13.1)$ & $<0.001$ \\
\hline $\begin{array}{l}\text { Confidence to take a leadership role in one's trust/organisation } \\
\text { in supporting trainees returning to training / developing return to } \\
\text { training resources }\end{array}$ & $50.9(24.8)$ & $78.7(17.0)$ & $<0.001$ \\
\hline
\end{tabular}

SD = standard deviation; SuppoRTT = Supported Return to Training. 
Box 3. Themes from semi-structured follow-up interviews with examples

Gaining new knowledge about the issues faced and availability of resources:

Broadly it was about what resources are available for trainees to support them, really.

How many trainees take time out and the challenges they face.

It was about services I didn't know existed.

The course increased confidence in supporting trainees:

Coming out, I feel more confident in what you can explain to trainees.

It was really useful after an experience where I didn't really know what to do.

I'm sure I will know what to do next time if I get a trainee returning.

Taking on new processes and roles as an educator:

I am now the point of contact at my trust and I have taken it forward which wasn't here before. I feel in the position to be able to give advice.

I've run a workshop for our educational supervisors.

Now I can point people in the right direction.

Trust and Health Education England processes need to be aligned:

If we're offering something, it needs to be joined up and working.

How do we incorporate this planning into processes including the ARCP? You could have a structured OOP placement form on the portfolio to form the basis to have these conversations.

In theory we should know who's taking time out and who is coming back in and when, but this isn't really as formally documented as it perhaps should be and that's something that could perhaps be improved upon.

Sharing ideas, learning from others and developing best practice in this area:

The discussions were good with people from other trusts' experiences.

Lots of people were doing different things and had ideas that I hadn't thought about.

Trainees are quite self-entitled and if you don't respond quickly then they can be quite shirty with you.

$\mathrm{ARCP}=$ Annual review of Competence Progression; OOP = out of programme.

Course feedback highlighted issues within current healthcare systems which impact on trainers' ability to support trainees. Rates of burnout, emotional exhaustion and anxiety are increasing among hospital consultants. As this is affecting the level of patient care, they feel able to provide, it is not a large stretch to see that it can also impact on their ability to support and teach trainees. ${ }^{18,19}$ Future courses and training initiatives could focus more specifically on these topics, perhaps including self-care or personal management strategies within group discussions creating a 'dedicated place for meeting, thinking and exchanging. ${ }^{20}$

The strengths of this project included the multiprofessional design and successful delivery of three standardised courses facilitated by similar faculty members in addition to the mixed methods approach to evaluation. Thematic analysis showed that the initially stated aims and outcomes for the course were met, and delegates achieved their personal aims and learning needs. Follow-up interviews demonstrated not only retention of topics learned but also reflection on issues discussed at the course and positive changes in behaviour. The course therefore met Level 3 on Kirkpatrick's levels of evaluating training programmes (Level 1 = reaction; Level 2 = learning; Level 3 = behaviour; and Level 4 = results). ${ }^{12}$ Creating and delivering an education programme providing results (Level 4 ) is a challenge and a followup study could be undertaken to assess this further.

The small numbers involved, however, limit the conclusions we can draw from the project. Furthermore, the course was designed to attend to the needs of physicians and whether there are specific needs for trainers from different specialties is yet to be elucidated. Consideration of allied healthcare professionals returning to practice could also be important, although the varying ways of supervising and training could impact on the utility of a similar course, and adjustments would be needed. In addition, this course took place in one region (with an increased rate of trainees out of programme) and local issues may differ elsewhere. Feedback suggested increasing the evidence base of best practice for supporting returning trainees and we hope this study will add benefit in this regard in an area where, to our knowledge, there have been no other similar initiatives to date.

\section{Supplementary material}

Additional supplementary material may be found in the online version of this article at www.rcpjournals.org/clinmedicine:

S1 - Case studies reflecting the major needs of trainees returning to practice.

S2 - Validated pre- and post-course questionnaires.

S3 - Return to practice follow-up interview.

\section{References}

1 Grace SE, Korinek EJ, Weitzel LB, Wentz DK. Physicians re-entering clinical practice: Characteristics' and clinical abillities. J Contin Educ Health Prof 2010:30:180-6.

2 Health Education England. Supported return to training. NHS. www.hee.nhs.uk/sites/default/files/documents/Supported \% 20 Return \% 20to \% 20Training.pdf [Accessed 20 August 2019].

3 Agius S], Tack G, Murphy P, Holmes S, Hayden J. Why do medical trainees take time out of thier specialty training programmes? $\mathrm{Br}$ ] Hosp Med 2014;75:584-9.

4 Blackmore C, Austin J, Lopushinsky SR, Donnon T. Effects of postgraduate medical education 'boot camps' on clinical skills, knowlege and confidence: a meta-analysis. J Grad Med Educ 2014;6:643-52.

5 Bruce CT, Thomas P, Yates BJ. Burnout and psychiatric morbidity in new medical graduates. Med J Aust 2005;182:599.

6 Gowland EH, Ford C, Le Ball K. The comeback: supporting higher specialty trainees returning to practice. Commentary 2016.

7 Academy of Medical Royal Colleges. Return to practice guidance. AOMRC, 2017. www.aomrc.org.uk/wp-content/uploads/2017/06/ Return_to_Practice_guidance_2017_Revison_0617-2.pdf [Accessed 20 August 2019].

8 General Medical Council. The state of medical education and prac tice in the UK. London: GMC, 2019. www.gmc-uk.org/-/media/ documents/somep-2019_full-report_pdf-81131156.pdf?! 
$a=$ en\&hash=B80CB05CE8596E6D2386E89CBC3FDB60BFAAE3CF [Accessed 14 April 2020].

9 Health Education England. Supported Return to Training: SuppoRTT. NHS. www.hee.nhs.uk/our-work/supporting-doctorsreturning-training-after-time-out [Accessed 20 August 2019].

10 Nash E, Curry JI, Blackburn SC. Returning to the theatre after an interval. Bull R Coll Surg Engl 2018;100:277-81.

11 van Boxel E, Watson S, Dawkins S et al. The 'Mother' score - an evidence-based assessment of predicting trainee confidence on return to work after maternity leave. Developing Excellence in Medical Education Conference 2017 abstracts poster submission 2017. www.demec.org.uk/demecassets/3-76.pdf [Accessed 20 August 2019].

12 Kirkpatrick DL. Evaluating training programs, 2nd edn. San Francisco: Berrett-Koehler, 1998.

13 Gale NK, Heath G, Cameron E, Rashid S, Redwood S. Using the framework method for the analysis of qualitative data in multidisciplinary health research. BMC Med Res Methodol 2013;13:117.

14 Yardley S, Irvine AW, Lefroy J. Minding the gap between communication skills simulation and authentic experience. Med Educ 2013:47:495-510.

15 Royal College of Physicians. Women and medicine: The future. London: RCP, 2009. www.rcr.ac.uk/sites/default/files/RCP_
Women_\%20in_\%20Medicine_\%20Report.pdf [Accessed 20 August 2019].

16 Rimmer A. Postgraduate training will be more flexible under new standards, says GMC. BMJ 2017;357:j2585

17 Health Education England. Enhancing junior doctors' working lives - annual progress report 2019. London: HEE, 2019. www.hee. nhs.uk/sites/default/files/documents/EJDWL_Report_Edit_FINAL. pdf [Accessed 20 August 2019].

18 Khan A, Teoh KR, Islam S, Hassard J. Psychosocial work characteristics, burnout, psychological morbidity symptoms and early retirement intentions: a cross-sectional study of NHS consultants in the UK. BMJ Open 2018;8:e018720.

19 Taylor C, Graham J, Potts HW, Richards MA, Ramirez AJ. Changes in mental health of UK hospital consultants since the mid-1990s. Lancet 2005;366:742-4.

20 Gerada C, Chatfield C, Rimmer A, Godlee F. Making doctors better. BMJ 2018;363:k4147

Address for correspondence: Dr Jonathan Birns, Department of Ageing and Health, St Thomas' Hospital, Westminster Bridge Road, London SE1 7EH, UK.

Email: jonathan.birns@gstt.nhs.uk

\section{Royal College of Physicians}

\section{Management and care of tracheostomised patients with prolonged disorders of consciousness (PDOC) during COVID-19}

This guidance, which supplements the PDOC national clinical guidelines published in March 2020, supports decision-making in tracheostomised patients with PDOC and takes into account the requirements to protect patients and staff from the risks of acquiring COVID-19.

Download the guidelines: www.rcplondon.ac.uk/pdoc-covid-19 